\title{
Industrially relevant ethylene trimerization catalysts and processes
}

\author{
Subhas Madavu Salian ${ }^{1}$ (1) $\cdot$ Mahuya Bagui $^{1} \cdot$ Raksh Vir Jasra $^{1}$
}

Received: 3 June 2021 / Accepted: 2 September 2021 / Published online: 12 September 2021

(c) The Author(s) 2021

\begin{abstract}
1-Hexene is one of the comonomers used to produce mainly low linear density polyethylene (LLDPE) and high-density polyethylene (HDPE). The production of 1-hexene by ethylene trimerization method gained much interest in petrochemical industry due to its high selectivity towards 1-hexene in comparison to traditional ethylene oligomerization method. In literature, many catalyst systems are reported for ethylene trimerization reaction, but only few of them qualify for the commercial applications. In the present review, activity and selectivity of commercially viable catalyst systems and amount of polyethylene formed as a by-product on using these catalyst systems were discussed. Special attention is given to Chevron Phillips ethylene trimerization technology which is one of the dominant technologies in the production of 1-hexene. The challenges such as fouling issues at commercial plant due to polyethylene by-product formation were discussed and the progress made to overcome the challenges were also discussed. New generation nontoxic titanium catalysts look promising and challenges involved in commercializing these catalysts were presented in the review.
\end{abstract}

\section{Graphic abstract}

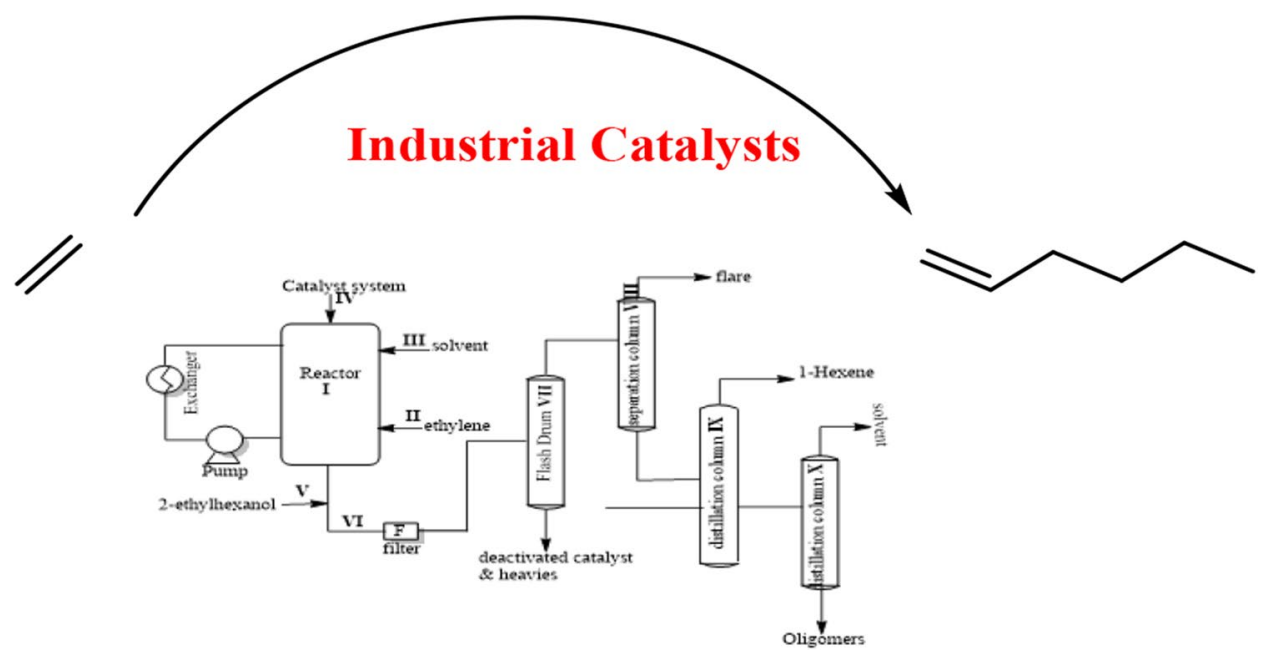

Keywords 1 -Hexene $\cdot$ Ethylene trimerization $\cdot$ Commercial catalysts $\cdot$ Fouling $\cdot$ Polyethylene

\section{Introduction}

Subhas Madavu Salian

subhas.salian@ril.com

1 Reliance Technology Group, Reliance Industries Ltd, Vadodara Manufacturing Division, Vadodara, Gujarat 391346, India
Linear alpha olefins (LAOs) or 1-alkenes in the range of $\mathrm{C}_{4}-\mathrm{C}_{20}$, are useful intermediates for manufacturing of a wide range of products like detergents, polymers, synthetic lubricants, plasticizer alcohols, etc. Among LAOs, the lower linear olefins such as 1-butene, 1-hexene and 1-octene are 
used as comonomers for the preparation of polyethylene such as HDPE, LLDPE [1]. The addition of comonomer to polyethylene alters the polymer properties such as melt index, density, molecular weight distribution, etc. [2]. The comonomers create a short chain branching in the polymer backbone, preventing polymer chains from packing together tightly, thus lowering product density. The higher the comonomer concentration, the lower is the density of the resin. In addition to controlling density, alpha olefin comonomers modify the processing and mechanical properties of the polymers. In general, HDPE and LLDPE have comonomer incorporation of about 2-4 \& 8-10 weight\%, respectively [3]. The chain length of the comonomer also influences the above-mentioned properties. The properties of LLDPE, prepared using 1-hexene as comonomer are much superior than those of LLDPE containing 1-butene as comonomer [4]. Rheological study has shown that such polymer's performance properties such as impact (toughness) and tear strength increase with an increase in the comonomer length, i.e., 1-butene, 1-hexene, 1-octene [5].

Among lower alpha olefins, longer length carbon chain 1-octene may be the favourable comonomer for ethylene polymerization, but challenges are involved in development of selective ethylene tetramerization technology for production of 1-octene. The current Sasol ethylene tetramerization technology shows 1-octene selectivity of only $70 \%$ and gives other products, like 1-hexene. The formation of 1-octene during the ethylene tetramerization requires the formation of less favoured 9-membered ring intermediate, but unfortunately few of them break down at stage of 7-membered ring intermediate to give 1-hexene. Hence 1-octene technology is not readily available. Moreover, polyethylene containing 1-hexene as comonomer shows superior properties than 1-butene-polyethylene. All these factors create demand for 1-hexene worldwide.

After the development of metallocene-based technology for production of polyolefins, the demand for 1-hexene gradually increased over the years and 1-hexene is one of the preferred comonomers to produce metallocene grade LLDPE (mLLDPE). mLLDPE draws special interest because of their excellent properties like flexibility, enhanced toughness, good clarity, and elasticity [6]. The market demand for mLLDPE has been increased over the years due to their application in flexible packaging, food and industrial packaging, agricultural industry, etc.

Overall, the global demand for 1-hexene in 2019 was estimated to be about 1 million MT, among which $73 \%$ of total global demand originated from LLDPE, $21 \%$ from HDPE (Fig. 1). Other applications of 1-hexene include production of heptanoic acid derivatives, manufactured by hydroformylation of 1-hexene. The esterification of heptanoic acid with neopentylglycol yields neopolyol esters (NPE). Heptanoic acid-based NPEs are used as synthetic



Fig. 1 1-Hexene demand in 2019

lubricant base stocks mainly in aircraft jet engines and small amount of it is used in automotive sector. Small volumes of heptanoic acid as their esters are used in the production of flavour and fragrance chemicals and peroxy chemicals. For example, ethyl heptanoate or allyl heptanoate with fruity or pineapple notes are commonly used flavors in the food industry. Sodium salt of n-heptanoic acid is used as corrosion inhibitor to protect copper, iron, aluminum and zinc-based materials. 1-Hexene is also used to produce n-hexyl mercaptan, utilized as an agricultural chemical intermediate. Unlike 1-butene and1-octene, 1-hexene has very limited application in the manufacturing of polyolefin elastomers (POE) and polyolefin plastomers (POP).

Currently, 1-hexene is produced predominantly by (i) ethylene oligomerization (ii) ethylene trimerization (iii) Fischer Tropsch technology and (iv) small fraction by ethylene tetramerization technology. The top producers of 1-hexene are Chevron Phillips, Sasol, Shell Chemical, Ineos and Saudi Polymers who accounted for approximately $78 \%$ of world's 1-hexene production (Fig. 2). Among top producers, Chevron Phillips is the leading supplier of 1-hexene due to their successful trimerization technology utilizing chromiumpyrrole catalyst system. Previously Sasol was the major producer of 1-hexene based on their Fischer Tropsch technology. Recently Sasol developed tetramerization technology, which produces mixture of 1-octene and 1-hexene. The Inoes and Shell produce 1-hexene from LAO technology where 1 -hexene is separated from other alpha olefin fractions. The Saudi Polymers uses Chevron Phillips trimerization technology for producing 1-hexene with 100 KTA plant capacity. The minor contributors to the world's 1-hexene supply are 


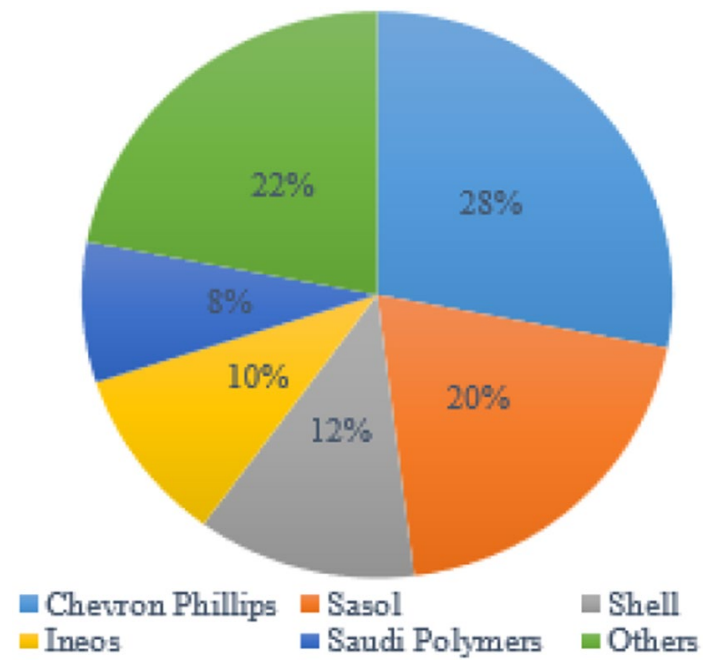

Fig. 2 Global top manufacturers of 1-hexene

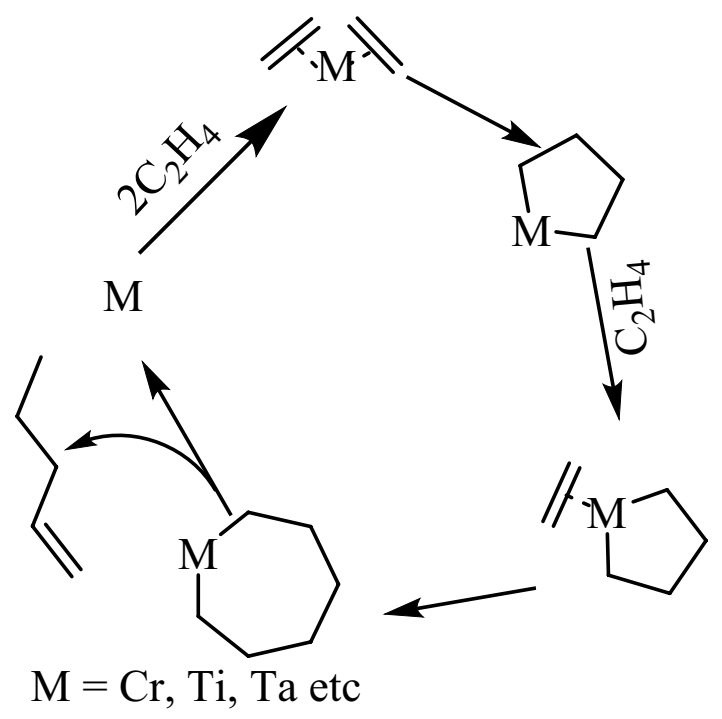

Scheme 1 Mechanism for ethylene trimerization

Sinopec Beijing Yanhua Petrochemicals, Mitsuai Chemicals with plant capacity of 50KTA and 30KTA, respectively.

The general mechanism of ethylene trimerization, proposed by Briggs, involves the formation of metallacyclic intermediates which was supported by experimental and theoretical findings. As shown in Scheme 1, initially, two molecules of ethylene coordinate the catalyst center, followed by formation of metallacyclopentane. The metallacyclopentane then undergoes expansion with addition of a third molecule of ethylene to form seven-membered metallacycloheptane. Finally, metallacycloheptane undergoes $\beta$-elimination followed by reductive elimination to produce1-hexene with regeneration of the catalyst. The formation of by-products such as 1-butene, 1-octene, internal hexenes, decenes, higher olefins and smaller amount of polyethylene during ethylene trimerization can also be explained by above mechanism. For example, decenes are formed by co-trimerization of 1-hexene with two molecules of ethylene. The 1-hexene and ethylene reacts to form five-membered butyl-substituted $\mathrm{Cr}$ metallacycle followed by addition of one more molecule of ethylene to give butyl-substituted seven-membered $\mathrm{Cr}$ metallacycle which decomposes into mixture of decenes. The proposed reaction pathway was investigated by Y. Yang and co-workers by controlled experiments where addition of 1-hexene to ethylene trimerization reaction showed increase in selectivity of decenes and addition of 1-butene decreased the decene selectivity and increased the octene selectivity [7].

Since first report of Phillips ethylene trimerization catalyst system, major petroleum companies such as Sumitomo Chemical Company, BASF, Idemitsu Kosan Company, Chinese Petroleum Group, Sasol Technology, Beijing Yanshan Petrochemical Company, etc. have disclosed ethylene trimerization technologies with emphasising on improvements in catalysts and processes over existing systems in multiple patents and publications $[8,9]$. These ethylene trimerization processes utilize inexpensive ligands and activators, use of expensive activator such as MAO in low quantity coupled with lower amount of polyethylene (PE) formation. Besides, high thermal stability, activity and selectivity of catalyst systems make them as potential candidates for the industrial applications. This review covers some of the potential catalyst systems, selected from these publications and patents.

\section{Chromium-based catalytic systems}

Various metal catalyst systems such as chromium, titanium, tantalum have been reported for ethylene trimerization reaction till date. Among them, chromium-based systems are reported in large numbers in comparison to other systems [9]. Initially, Union Carbide researchers discovered the potential of chromium-based catalysts for selective ethylene oligomerization [10]. In 1977, they observed coproduction of 1-hexene along with high molecular weight polyethylene during ethylene polymerization catalysed and activated by chromium tris(2-ethylhexanoate) and partially hydrolysed triisobutylaluminium, respectively. Addition of 1,2-dimethoxyethane (1,2-DME) to this system significantly increased the selectivity of 1-hexene, indicating the effect of the ligands towards oligomers formation [11]. Following this report, researchers explored the use different types of ligands in ethylene oligomerization reaction to increase the selectivity of alpha olefin. The succeeding section describes various Cr-based catalytic systems which are industrially important for selective oligomerization of ethylene. 


\section{Chevron Phillips Cr-pyrrole catalyst system}

The real breakthrough was achieved with the discovery of Phillips trimerization catalyst, which contained a pyrrole type ligand along with chromium compound and activators, i.e., alkyl aluminums. The ethylene trimerization reaction catalysed by Phillips catalyst system showed productivity of $156.7 \mathrm{~kg} \mathrm{C} / \mathrm{g} \mathrm{Cr} / \mathrm{h}$ at a reaction temperature of $115^{\circ} \mathrm{C}$ and ethylene pressure of $100 \mathrm{bar}$. The product analysis exhibited $\mathrm{C}_{6}$ selectivity, exceeding $93 \%$ with purity of 1-hexene above $99 \%$ in the $\mathrm{C}_{6}$ fraction. The main by-products were decenes with trace amount of polymer (Scheme 2) [12]. In 2003, the first commercial plant for 1-hexene became operational at Qatar Chemical Company in Qatar with a capacity of 47KTA using above catalyst system. Later in 2011, another plant was commissioned with production capacity of 100 KTA at Saudi Polymers, Saudi Arabia. The third plant was commissioned in 2014 at Texas, USA with an aim to produce 1-hexene around 250 KTA per annum [13, 14].

The activity of the Phillips catalytic system strongly depends on factors like the purity of catalyst components, ratio of each components and the method of their preparation [15]. The catalyst system is prepared in toluene under inert atmosphere by mixing Cr-2-ethylhexanoate $\left[\mathrm{Cr}(\mathrm{EH})_{3}\right]$, 2,5-dimethylpyrrole (DMP), triethylaluminum $\left(\mathrm{Et}_{3} \mathrm{Al}\right)$, $\mathrm{AlEt}_{2} \mathrm{Cl}$ in a molar ratio of 1:3:11:8, respectively (Scheme 2) [12].

The performance of this catalyst was very sensitive to reaction medium. The higher catalytic activity was observed in hydrocarbon solvents like cyclohexane, methylcyclohexane, heptane, etc. than that in aromatic solvents such as toluene, xylene, etc. The active species for ethylene trimerization is low valent $\mathrm{Cr}$ (I) metal species which are known to be stabilized by aromatic compounds. Amir Jabir et al. isolated the ethylene trimerization active species (2), shown in Scheme 3, which failed to produce 1-hexene while ethylene trimerization reaction was carried out in toluene, but it could produce significant amount of 1-hexene in methylcyclohexane. This is because toluene acts as poison in Phillips ethylene trimerization by forming $\mathrm{Cr}$ (I) - arene complex, whereas in methyl cyclohexane, the active sites are free to bind to ethylene without any competition of other $\pi$ systems [16].

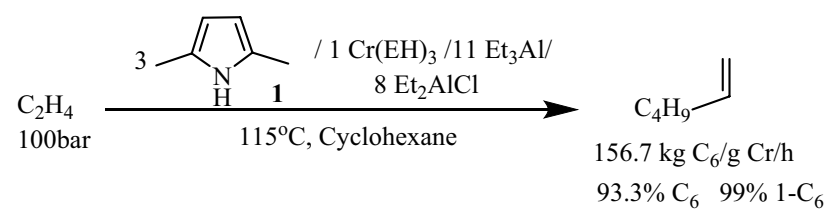

Scheme 2 Chevron Phillips Cr-pyrrole catalyst system



Scheme 3 Synthesis of complex 2

High productivity of the Phillips catalyst in presence of 2,5-dimethyl pyrrole ligand intrigued researchers to study the activity of various pyrrole derivatives for the ethylene trimerization [17]. Sydora et al. at Phillips Chevron performed the oligomerization reaction to compare the catalytic behaviour of different pyrroles under standard reaction conditions [18]. The pyrrole derivatives such as 2,5-dimethylpyrrole, 2,5-dibenzylpyrrole, 2,4-dimethylpyrrole, pyrrole, 2,5-diethylpyrrole, and 2-methyl-4-isopropylpyrrole were investigated for productivity and selectivity of 1-hexene at different reaction conditions. In industry, high reaction temperature is beneficial in terms of plant operation as at higher temperature, solubility of polymeric by-product increases in the reaction medium and pipelines are less vulnerable to choking. The polymer fraction is formed as a by-product in ethylene trimerization and use of reaction temperature above the melt temperature of the polymer is highly recommended. Figure 3 compares the productivity of 1-hexene for each pyrrole derivatives at reaction temperature of $115^{\circ} \mathrm{C}$.

It can be seen from Fig. 3 that substituted pyrroles exhibited better productivity in comparison to unsubstituted pyrroles. Among substituted pyrroles, 2, 5-disubstituted pyrrole showed four times higher productivity than 2, 4-disubstituted pyrroles. Additionally, steric effect of pyrrole ligands also plays a major role on productivity. The sterically hindered,

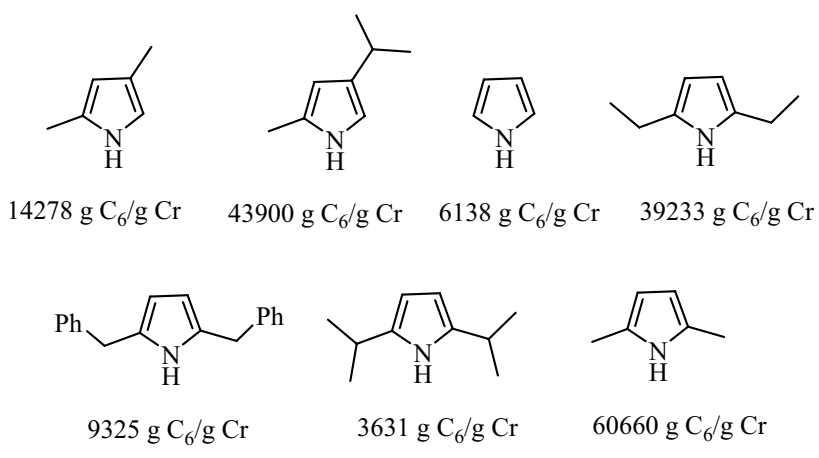

Fig. 3 Pyrrole-based ligands and their catalytic activity for ethylene trimerization 


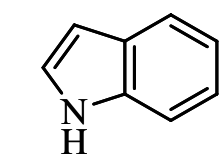

$789 \mathrm{~g} \mathrm{C}_{6} / \mathrm{g} \mathrm{Cr}$

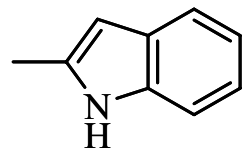

$3508 \mathrm{~g} \mathrm{C}_{6} / \mathrm{g} \mathrm{Cr}$
Fig. 4 Indole-based ligands and their catalytic activity for ethylene trimerization

2,5-diisopropylpyrrole showed low productivity (3,631 g $\mathrm{C}_{6} / \mathrm{g} \mathrm{Cr}$ ) in comparison to less sterically hindered 2,5-diethylpyrrole $\left(39,233 \mathrm{~g} \mathrm{C}_{6} / \mathrm{g} \mathrm{Cr}\right)$.

Besides pyrrole ligands, the Phillips trimerization catalyst systems, prepared from indole or substituted indoles, were also evaluated for ethylene trimerization under standard reaction conditions (Fig. 4). The catalyst systems prepared from indole derivatives showed significantly lower productivity than the pyrrole derivatives despite of their similarity in structures. For example, productivity of $789 \mathrm{~g} \mathrm{C}_{6} / \mathrm{g} \mathrm{Cr}$ was observed with indole system in comparison to $3508 \mathrm{~g} \mathrm{C}_{6} / \mathrm{g}$ $\mathrm{Cr}$ with pyrrole system.

Apart from ligands, another important component in Phillip's catalytic system is the metal precursor, i.e. $\left[\mathrm{Cr}(\mathrm{EH})_{3}\right]$. The common method of preparation of $\mathrm{Cr}(\mathrm{EH})_{3}$ involves the reaction of chromium salts with sodium-2-ethylhexanoate in either organic solvent or water. The purity, method of preparation and composition of $\mathrm{Cr}(\mathrm{EH})_{3}$ can have a great influence on productivity and selectivity of 1-hexene in typical ethylene trimerization reaction [19]. $\mathrm{The} \mathrm{Cr}(\mathrm{EH})_{3}$ is commercially available as $40-70 \%$ solution in mineral oil, where the chromium content varies in the range of $8-10$ wt $\%$ based on the lot number [20]. Jeon et al. observed the inconsistent performance of commercial $\mathrm{Cr}(\mathrm{EH})_{3}$ on using different lot numbered samples, procured from same manufacturer for the ethylene trimerization [21]. The batch-tobatch variations in the performance of some of the commercial $\mathrm{Cr}(\mathrm{EH})_{3}$ samples may be due to the presence of carboxylic acid and residual water molecules coordinated to metal centre. These coordinated species are incompatible with the type of activators (i.e. alkylaluminiums), used for ethylene trimerization and hence excess amount of activator is required to achieve the desired catalytic activity which is unfavourable for the entire process economics. However, as reported by two independent research groups, the aquated $\mathrm{Cr}(\mathrm{EH})_{3}$ shows almost similar or better productivity and selectivity in comparison to conventional Chevron Philips catalyst system prepared from anhydrous $\mathrm{Cr}(\mathrm{EH})_{3}$ $[21,22]$. The aquated $\mathrm{Cr}(\mathrm{EH})_{3}$ is prepared by reaction of hydrated chromium chloride with sodium-2-ethyl hexanoate in aqueous medium [23]. Jeon et al. proposed a molecular formula of $\mathrm{Cr}(\mathrm{EH})_{2} \mathrm{OH}$ for the aquated $\mathrm{Cr}(\mathrm{EH})_{3} \mathrm{com}-$ plex. The aquated complex is found to be highly soluble in hydrocarbon solvent such as hexane, cyclohexane, benzene, or toluene. The catalyst prepared using $(\mathrm{EH})_{2} \mathrm{CrOH}$ in cyclohexane exhibited activity of $54,000 \mathrm{~kg} \mathrm{C} / \mathrm{mol} \mathrm{Cr} / \mathrm{h}$, substantially higher than that of the catalyst prepared using the commercial $\mathrm{Cr}(\mathrm{EH})_{3}\left(16000 \mathrm{~kg} \mathrm{C}_{6} / \mathrm{molCr} / \mathrm{h}\right)$ in toluene. Moreover, for $\mathrm{Cr}(\mathrm{EH})_{2} \mathrm{OH}$, cyclohexane could be used as a common solvent for both catalyst preparation and as reaction medium. Use of the same solvent for catalyst preparation and as reaction medium in trimerization reaction brings in huge benefit in operating the process in industry. In case of commercial Chevron Phillips catalyst system, toluene was used as a catalyst preparation medium and cyclohexane as a reaction medium for ethylene trimerization.

The analytical characterization of commercial $\mathrm{Cr}(\mathrm{EH})_{3}$ sample showed the presence of high nuclear chromium clusters which decreases their solubility in aliphatic hydrocarbons like n-hexane, cyclohexane, etc. Hence preparation of catalyst system requires the use of aromatic solvent like toluene, xylene which is less desirable in ethylene trimerization. To overcome these challenges, Sydora et al. reported the synthesis of monomeric, neutral homoleptic $\mathrm{Cr}(\mathrm{EH})_{3}$ under anhydrous conditions. The $\mathrm{Cr}$ complex made by this way is soluble in aliphatic solvents. Moreover, there is no residual water or acid moieties, making the complex compatible with the activators such as alkyl aluminium [24].

Apart from catalyst composition, catalyst concentration, the reaction temperature, ethylene pressure, too play important roles to influence the productivity and selectivity of 1-hexene and the amount of polymer by-product formation in ethylene trimerization process. Tang et al. studied the influence of reaction temperature for the catalyst system, consisting of $\mathrm{Cr}(\mathrm{EH})_{3}, 2,5$-dimethylpyrrole, $\mathrm{Et}_{3} \mathrm{Al}$, tetrachloroethane and observed that at low reaction temperature, ranging from 65 to $95{ }^{\circ} \mathrm{C}$, the activity increases with the increase in reaction temperature [25]. However, at a higher temperature of above $95^{\circ} \mathrm{C}$, the activity decreased with increasing temperature as shown in graph in Fig. 5. A similar study has been conducted at Chevron Phillips using their catalyst system where maximum productivity of 99,460 $\mathrm{gC}_{6} / \mathrm{gCr} / \mathrm{h}$ was observed at temperature of $95^{\circ} \mathrm{C}$ and after that it decreased with increasing reaction temperature. (at

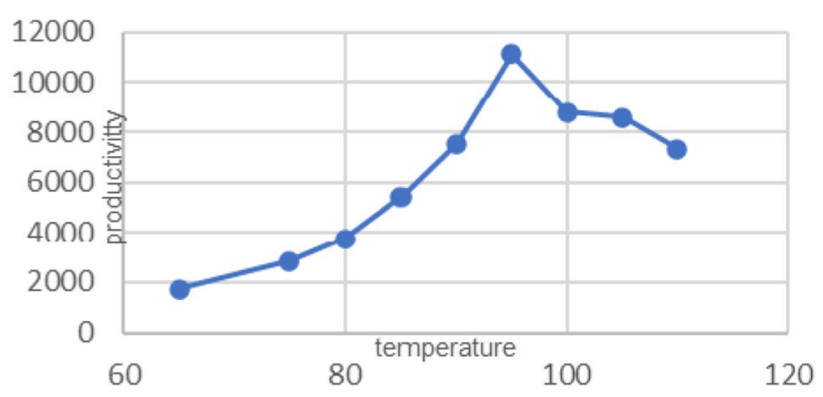

Fig. 5 Catalytic activity of Cr-Pyrrole system against temperature

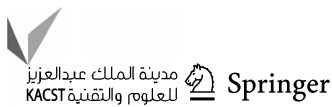


$135^{\circ} \mathrm{C}$, productivity is $25,900 \mathrm{gC}_{6} / \mathrm{gCr} / \mathrm{h}$ ). The loss of activity at high temperature might be due to the deactivation of the active sites or transformation of the active sites to a less active one [26].

The Chevron Phillips catalyzed ethylene trimerization produced by-products of $10 \mathrm{wt} \%$. The by-products include significant amount of decenes with a minor fraction of butenes, octenes, internal hexenes, higher olefins and polyethylene (polymer) [27]. The formation of polyethylene even in small amounts of $0.5-1.0 \mathrm{wt} \%$ poses serious complications in the plant operations. The polyethylene deposits on reactor walls, pumps, heat exchanger, etc. and deteriorates their performance. Also, over the period, the polymer accumulates in the reactor and chokes the pipelines when it passes through it. Therefore, the biggest challenge in ethylene trimerization plant is minimizing the polyethylene formation in the reactor and thereby avoiding the fouling of the reactor. Many research groups have characterized the nature of the polyethylene formed during ethylene trimerization reaction. Maniyak et al. confirmed the presence of butyl side chains in polyethylene backbone due to the incorporation of 1-hexene comonomer [10].

To address the issues related to polyethylene formation as one of the by-products, one of the attempts made is to use hydrogen as a co-feed during ethylene trimerization to reduce the formation of polyethylene and its stickiness. Hydrogen, known to act as chain-transfer agent, has been used to control the molecular weight of the polyethylene in the ethylene polymerization reaction [28]. BahriLaleh et al. investigated the effect of $\mathrm{H}_{2}$ on the polymer formation in ethylene trimerization reaction catalyzed by Chevron-Phillips trimerization catalyst system containing $\mathrm{Cr}(\mathrm{EH})_{3} / 2,5$-dimethylpyrrole/triethylaluminum/tetrachloroethane (TCE) [29]. The addition of hydrogen improved the efficiency of catalytic system by decreasing the polyethylene formation and increasing the catalytic activity. Tao Jiang and co-workers also investigated effect of hydrogen addition on the PNP/Cr(III)/MAO catalytic systems in ethylene tetramerization reaction where addition of hydrogen could reduce the molecular weight of polyethylene in addition to reduction in polyethylene formation [30]. The application of hydrogen in commercial plants of ethylene trimerization to reduce the formation of polyethylene can be witnessed from the patent literature [31].

Over the years, various theoretical investigations have been conducted on commercially successful Chevron-Phillips catalyst system to understand its fundamental aspects [32-34]. Detailed computational investigations, carried out by Yun Yang et.al, showed that $\mathrm{Cr}(\mathrm{I} / \mathrm{III})$ redox cycle is the prominent route among the $\mathrm{Cr}(\mathrm{I} / \mathrm{III})$ and $\mathrm{Cr}$ (II/IV) redox cycles for the selective ethylene trimerization [33]. Recently E. Naji - Rad et.al studied the effect of components of Chevron-Phillips catalyst system against productivity and selectivity using density functional theory (DFT) [34]. The prominent observation is increase of the steric hindrance on the pyrrole ring and less electron-withdrawing halides like chloride improves the catalytic performance.

To commercialize the Chevron Phillips ethylene trimerization process, numerous studies were carried out on plant operation. The outline of a commercial process is briefly shown in Fig. 6. The reaction usually occurs in bubble column reactor I to which polymer grade ethylene is fed through inlet line II from the bottom of the reactor [30]. The solvent, cyclohexane is pumped using inlet line III. The catalyst system consisting of $\mathrm{Cr}(\mathrm{EH})_{3} / \mathrm{DMP} \mathrm{Et}_{3} \mathrm{Al} / \mathrm{AlEt}_{2} \mathrm{Cl}$ is introduced to reactor through inlet line $\mathbf{I V}$.

The reactor temperature is maintained at $115^{\circ} \mathrm{C}$ by water cooled exchanger. The reactor pressure is maintained at 800 psi during trimerization reaction with residence time of 4-6 h. 1-hexene is formed in the reactor with high selectivity and additionally small amount of higher olefins such as octene, decenes, polymer, etc. are also formed through
Fig. 6 General process flow diagram for ethylene trimerization




unavoidable side reaction. Trimerization reactor effluent comprising 1-hexene, other alpha olefins, polymers, unreacted ethylene and catalyst residues is removed via effluent line VI. The stream of 2-ethylhexanol is fed via inlet line $\mathbf{V}$ into effluent line VI to deactivate the catalyst system. A filter can be used to remove solid particles such as undesirable polymer, catalyst residues, etc. from effluent line $\mathbf{6}$. If the reactor effluent stream in effluent line VI is maintained at a temperature above the melt temperature of the polymer, then filter may not be useful to trap the polymer by-product. However, if the reactor effluent stream in effluent line VI is allowed to cool, polymer by-product precipitates out and filter can be used to separate them. The reactor effluent is next pumped to flash drum VII where catalyst residues and other heavies are separated from lighter olefins and reaction solvent. The bottom portion of flash drum is connected to downstream processing unit to remove the heavy oligomers, polymers and catalyst residues. Reactor effluent is pumped to ethylene recovery unit VIII where ethylene is separated and sent back to either reactor or flare unit. Distillation column IX is used to separate desired 1-hexene. Next, cyclohexane and other higher oligomers are sent to distillation column $\mathbf{X}$. The cyclohexane is separated and sent back to the reactor for the reuse.

In ethylene trimerization technology, cost of plant operation depends on the frequency of fouling of a reactor and downstream equipments in the plant. Because on fouling, it is necessary to shut down the plant to clean the clogged polymers and deactivated catalyst residues from the reactor and downstream equipment units. The cleaning process interrupts the production of 1-hexene, and it costs loss of manhours and need of equipment for cleaning operation. A few methods have been developed in the plant for dealing with the issue of fouling. One of the common methods or procedures is to wash the reactor and pipelines with a suitable solvent at temperature of $60-70{ }^{\circ} \mathrm{C}$ higher than the reaction temperature. Usually, the solvent used in this method is the same as that of the reaction solvent and it is circulated at high temperature for several hours to remove most of the deposited polymeric residues. As mentioned earlier, by-product polyethylene is sticky in nature, binds hard to the plant equipment. To minimize the deposition of polymers in the reactor and pipings, the best approach is to coat the surfaces of the reactor and pipings with fluoropolymer. The coating of fluoropolymer is inert towards ethylene oligomerization reaction and can reduce the deposition of polymers on its surfaces.

Another method available for separating polymer byproduct is cooling the reactor effluent and filtering the precipitated polymer. In this method, reactor temperature is kept high enough to keep the polymers soluble in the reactor effluent. Once hot reactor effluent leaves the reactor, it is treated with alcohol to deactivate the catalyst system. The reactor effluent is then cooled to precipitate the polymer and the precipitated polymer is separated by filtration technique. Since part of the polymer remains soluble in filtered solution, the soluble by-product reaches the distillation column and over the period, it accumulates at distillation column and makes the polymer separation process inefficient. To avoid fouling of the distillation column, best method for smooth operation of the plant is to pump hot reactor effluent to the flash separator unit where unreacted ethylene, 1-hexene, solvent and low boiling by-products are separated by flash vaporization. At the downstream, effluent stream containing polymers, heavy oligomers and catalyst residues is sent to steam stripping vessel. In steam vessel, the polymers can be separated from liquids by continuous steam distillation process [35].

\section{Mitsubishi chemicals corporation Cr-pyrrole catalyst system}

With an objective to improve the existing Phillips catalytic system, Mitsubishi chemical corporation reported various Cr-Pyrrole-based systems for trimerization of ethylene. The researchers at Mitsubishi investigated the activity of the catalyst system by introducing a chloride source such as $\mathrm{CHCl}_{2} \mathrm{CHCl}_{2}, \mathrm{CCl}_{3} \mathrm{CCl}_{3}$ and $\mathrm{CCl}_{4}$ [36].

The best result was obtained by employing the catalytic system, consisting of $\mathrm{Cr}(\mathrm{EH})_{3}$, 2,5-dimethylpyrrole, hexachloroethane and $\mathrm{Et}_{3} \mathrm{Al}$ in molar ratios of 1:6:4:40 which showed unprecedented catalyst activities up to $3,780,000 \mathrm{~g} / \mathrm{g}$ $\mathrm{Cr} / \mathrm{h}$ at $105^{\circ} \mathrm{C}$ and 50 bar of ethylene pressure (Scheme 4). The above reaction resulted in $\sim 99.96 \%$ of liquid oligomers including $95.9 \%$ of hexenes, out of which $99.5 \%$ was 1 -hexene ( $95.4 \%$ overall 1 -hexene).

H. K. Luo et al. made the comparative study of effect of different halides like chloride, bromide, fluoride, etc. on chromium-pyrrole catalyzed ethylene trimerization and found that chloride acts as better promoter than that of a corresponding fluoride or bromide in achieving high 1-hexene selectivity and catalytic activity [37]. The chloro compounds containing geminal chloro groups with higher number of chloro substituents are found to be better candidate for ethylene trimerization reaction. They proposed facial coordination geometry of chromium catalyst system is much more

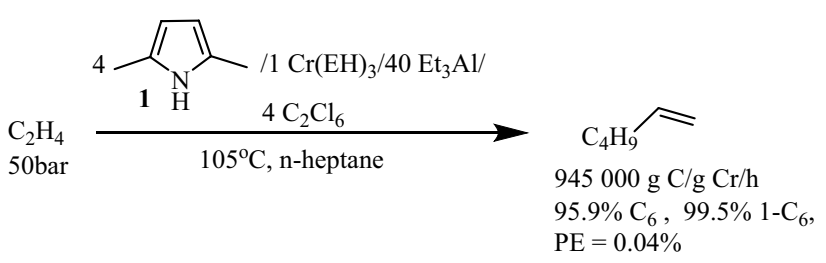

Scheme 4 Mitsubishi Chemicals Cr-Pyrrole-based catalyst system

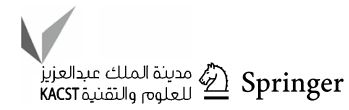


responsible for high activity and selectivity of 1-hexene than meridional coordination geometry. The halides like chloride stabilize the facial geometry complex of catalyst system through the coordination to chromium center in a certain way and hence shows enhanced activity.

\section{Axen's Alpha Hexol process}

In 1998, Institut Francais du Petrole (IFP) developed a new class of ligands, i.e., aryloxides for selective ethylene trimerization to 1-hexene. The catalyst composition, described in IFP's patent application, is obtained by mixing chromium precursor with aryloxyaluminium compound and a trialkylaluminium activator [38]. The catalytic system was prepared by mixing $\mathrm{Cr}(\mathrm{EH})_{3}$, bis(2,6-diphenylphenoxy) isobutyl aluminium, 3 and $\mathrm{Et}_{3} \mathrm{Al}$ at molar ratios of 1:8:8 (Scheme 5). When ethylene trimerization reaction was carried out using this catalyst system in toluene at $120^{\circ} \mathrm{C}$ and 50 bar of ethylene pressure, $74.5 \%$ of $\mathrm{C}_{6}$ with 1-hexene selectivity of $99.8 \%$ and $18 \%$ of the polymer was observed. Under this condition, the catalyst activity was found to be low, $3654 \mathrm{~g} \mathrm{C} / \mathrm{g} \mathrm{Cr} / \mathrm{h}$.

Two years later, IFP developed a new catalyst system where aryloxyaluminium compound were replaced by an aryloxy component having general formula of $M(R O)_{2-n} X_{n}$ wherein $\mathrm{M}$ is magnesium, calcium, strontium or barium, $\mathrm{R}$ is substituted phenol and $\mathrm{X}$ is a halogen [39]. The ethylene trimerization reaction of $\mathrm{Cr}(\mathrm{EH})_{3}$, bis(2,6- diphenylphenoxy) magnesium, 4 and $\mathrm{Et}_{3} \mathrm{Al}$ at molar ratios of 1:1:3 in o-xylene at $140{ }^{\circ} \mathrm{C}$ and 30 bar of ethylene pressure afforded $84.4 \%$ $\mathrm{C}_{6}\left(98.9 \% 1-\mathrm{C}_{6}\right)$, and $11 \%$ of the polymer (Scheme 6). This catalyst system showed activity of 7,308 g C/g Cr/h which was much lower than Phillips catalyst system.

Later Sasol Technology improvised the IFP process by demonstrating that the catalytic activity could be gained by simple in situ mixing of the catalyst precursors instead of using a preformed aryloxy aluminium complex $\mathbf{3}$ or similar type metal complex 4 . They have shown that the combination of a 2,6-disubstituted phenol with a chromium source and an alkylaluminium activator is an effective catalyst for the selective trimerization of ethylene. In addition to this, they found that aromatic ether solvent such as anisole are better solvent where substantial increase in both the activity

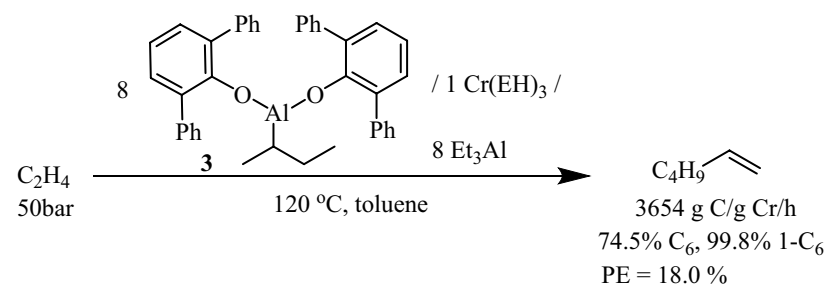

Scheme 5 IFP's aryloxyaluminium-based catalyst system

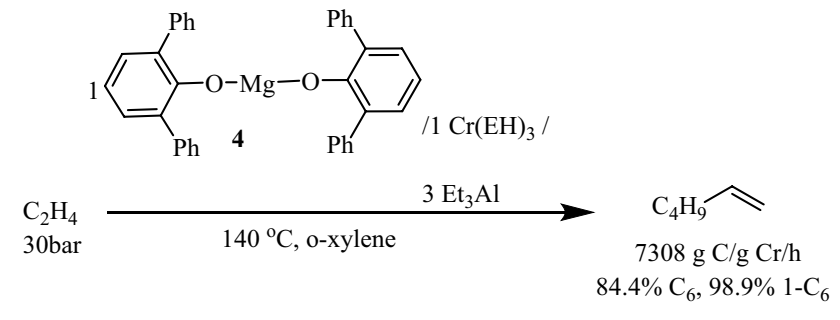

Scheme 6 IFP-Axen's aryloxymagnesium-based catalyst system

and the selectivity of the system is observed with decrease in the amount of polymeric side product [40].

On screening of various aryloxy ligands for ethylene trimerization, the best result was obtained when 2,6- diphenylphenol was used in combination with $\mathrm{Cr}(\mathrm{EH})_{3}$ and $\mathrm{Et}_{3} \mathrm{Al}$ in molar ratios of 14.5:1:20, respectively (Scheme 7). The reaction was carried out in anisole solvent at $130{ }^{\circ} \mathrm{C}$ under 37.5 bar of ethylene pressure. The product analysis showed $86.4 \%$ liquid oligomeric products, out of which $89.7 \%$ was $\mathrm{C}_{6}$, with $98.9 \%$ selectivity for 1 -hexene. The above reaction resulted in $13.6 \%$ polymer. The catalyst activity was around $22,769 \mathrm{~g} \mathrm{C} / \mathrm{g} \mathrm{Cr} / \mathrm{h}$. It is described that catalyst system is sensitive to temperature with respect to the product distribution. At low temperature $\leq 100^{\circ} \mathrm{C}$, the only product formed was the polymer while at temperature above $130{ }^{\circ} \mathrm{C}$, formation of higher oligomer predominated. The optimum temperature for best results was found to be in the range of 115 to $130{ }^{\circ} \mathrm{C}$ where major product was 1-hexene and minor products were higher oligomers and polymer.

From a commercialisation point of view, the major drawback of the process, based on aryloxide catalyst system, is the formation of polymer in a relatively large proportion (>9\%) as compared to Chevron Phillips $(<0.1 \%)$ necessitating an elaborate downstream process to separate polymer by-product.

Axens developed the IFPEN's aryloxymagnesium-based catalyst system further was translated into commercial technology under trade name of AlphaHexol ${ }^{\mathrm{TM}}$ technology. As per recent reports, Axens licensed its Alphahexol technology to Abu Dhabi Polymers Company Ltd (Borouge), a joint venture between Abu Dhabi National Oil Company (ADNOC) and Austria-based Borealis. The unit is projected to add a

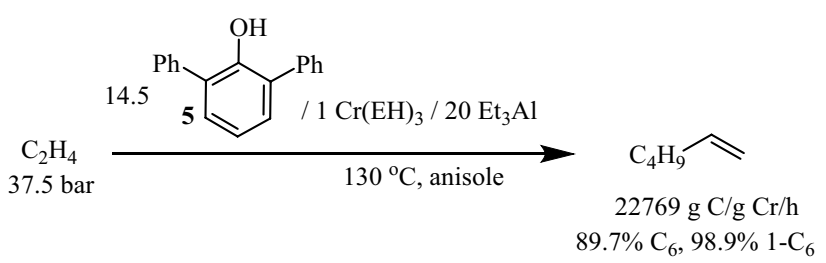

Scheme 7 Sasol's aryloxy ligand-based catalyst system 


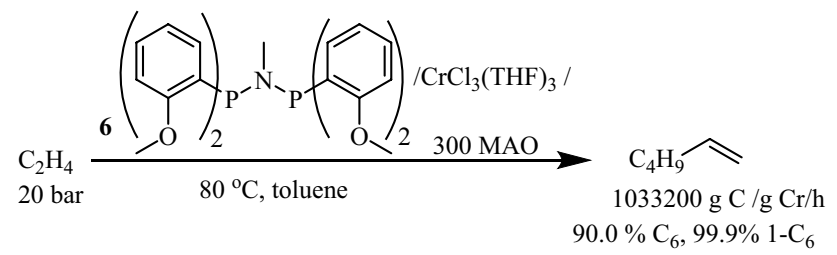

Scheme 8 BP's PNP ligand-based catalyst system

cumulative capacity of 75,000 tons/yr of 1-hexene through AlphaHexol ${ }^{\mathrm{TM}}$ technology.

\section{British petroleum Cr-PNP catalyst system}

In the early 2000, British Petroleum developed a chromium-based ethylene trimerization system with diphosphazane ligands of the type $\mathrm{Ar}_{2} \mathrm{PN}(\mathrm{Me}) \mathrm{PAr}_{2}$, where $\mathrm{Ar}$ is an O-methoxy-substituted aryl group [41, 42]. Previously, such type of diphosphazane ligands have been used as complexes of Pd to give ethylene/CO co-polymerisation catalysts [43] and as complexes of $\mathrm{Ni}$ to give ethylene polymerisation catalysts [44]. The screening of these ligands for ethylene trimerization showed that ligands bearing ortho-methoxy groups are active for selective ethylene trimerization. As depicted in Scheme 8, ligand $\mathbf{6}$ on formation of a complex with $\left[\mathrm{CrCl}_{3}(\mathrm{THF})_{3}\right]$ exhibited an impressive productivity of $1,033,200 \mathrm{~g} \mathrm{C} / \mathrm{g} \mathrm{Cr} / \mathrm{h}$. The product analysis showed $90 \%$ of $\mathrm{C}_{6}$ isomers, $1.8 \%$ of $\mathrm{C}_{8}$ isomers and $8.5 \%$ of $\mathrm{C}_{10}$ isomers with 1-hexene selectivity of $99.9 \%$ in $\mathrm{C}_{6}$ fraction.

This catalyst system is found to be thermally stable at $110{ }^{\circ} \mathrm{C}$ with productivity of $95,950 \mathrm{~g} \mathrm{C} / \mathrm{g} \mathrm{Cr} / \mathrm{h}$ at 8 bar of ethylene pressure and does not produce any measurable polymeric by-product in any run irrespective of the type of cocatalyst, chromium precursor or conditions used.

\section{Sasol Cr-SNS catalyst system}

In 2003, Sasol developed a new class of ligands, i.e., SNS ligands, alternative to previously reported PNP ligands [45]. These SNS ligands were easy to prepare and does not require expensive reagents. The reaction of SNS ligands with $\mathrm{CrCl}_{3}(\mathrm{THF})_{3}$ afforded complexes $\mathbf{7 a - 7 d}$ in $87-96 \%$ yields (Scheme 9, Table 1) [46]. The methyl-substituted 7a and ethyl-substituted $\mathbf{7 b}$ complexes showed similar activity and selectivity for ethylene trimerization, while complex 7c was found to be more active than the complexes $\mathbf{7 a}$ and $\mathbf{7 b}$. But 7a complex yields low amount of polymeric by-product compared to other catalysts which is more important for commercial operation. The complex $\mathbf{7 d}$ was significantly more soluble in toluene than $\mathbf{7 a - 7 c}$ due to the presence of long alkyl chains and exhibited high catalyst activity in the presence of a very low amount of MAO (100 equiv).

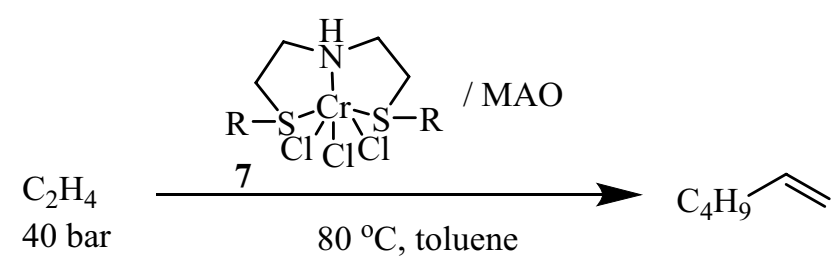

Scheme 9 Sasol SNS ligand-based catalyst system

\section{Cr-[NON] and [NSN] heteroscorpionate catalyst system}

Cr(III) complexes with NON and NSN heteroscorpionate ligands, derived from bis(pyrazol-1-yl) methane, is found to be active for ethylene trimerization to produce1-hexene with high selectivity [47]. The heteroscorpionate pyrazolyl ligands are inexpensive and are readily prepared by heating mixture of the appropriate acetal with 2 equivalents of pyrazole in the presence of $p$-toluenesulfonic acid. The corresponding $\mathrm{Cr}$ (III) complexes are prepared by one step reaction of appropriate pyrazolyl ligands with $\left[\mathrm{CrCl}_{3}(\mathrm{THF})_{3}\right]$ in THF at room temperature in good yields (85-91\%). The catalytic performances of both thioether based NSN complexes and ether based NON-complexes were evaluated toward ethylene trimerization. As depicted in Scheme 10, the catalyst 8a exhibited highest activity of $16,200 \mathrm{~g} \mathrm{C} / \mathrm{g}$ $\mathrm{Cr} / \mathrm{h}$ with 1 -hexene selectivity of $98.9 \%$ upon activation with 200 equivalents of MAO at $80{ }^{\circ} \mathrm{C}$ under ethylene pressure of 25 bar. The authors reported low polymer formation of less than $0.1 \mathrm{wt} \%$ for all catalyst systems expect for the catalyst system containing unhindered pyrazole units, e.g., 8c. The catalyst $8 \mathbf{a}$ has a long hexyl chain protruding from the pendant group which could be attributed to its better activity due to better solubility in toluene compared to catalysts, which has a shorter alkyl chain. A similar trend has been observed for the Sasol mixed heteroatomic SNS $\mathrm{Cr}$ systems, in which the $n$-decyl-substituted precatalyst $\left[\mathrm{CrCl}_{3}\left\{\mathrm{HN}\left(\mathrm{CH}_{2} \mathrm{CH}_{2}-\mathrm{S}^{n} \text { decyl }\right)_{2}\right\}\right], \mathbf{7 d}$ is significantly more active than those with shorter alkyl chains.

\section{SABIC-Linde Cr-PNPN catalyst system}

Rosenthal et al. in collaboration with SABIC and Linde have reported a new catalyst system for selective trimerization of ethylene based on $\left[\mathrm{CrCl}_{3}(\mathrm{THF})_{3}\right]$ as a chromium source, the ligand $\mathrm{Ph}_{2} \mathrm{PN}(i \mathrm{Pr}) \mathrm{P}(\mathrm{Ph}) \mathrm{N}(i \mathrm{Pr}) \mathrm{H}(9)$ and $\mathrm{Et}_{3} \mathrm{Al}$ as cocatalyst in toluene $[48,49]$. Under ethylene pressure of 30 bar and $50{ }^{\circ} \mathrm{C}$, the catalyst shows productivity of $20 \mathrm{~kg}$ $\mathrm{C} / \mathrm{g} \mathrm{Cr} / \mathrm{h}$ with $\mathrm{C}_{6}$ selectivity of $95.1 \%, 1-\mathrm{C}_{6}$ selectivity of $99.9 \%$ with $1.0 \%$ of polymer. The catalyst system is found to be inactive on use of chloride free chromium sources such as $\mathrm{Cr}(\mathrm{acac})_{3}, \mathrm{Cr}(\mathrm{EH})_{3}$, etc.

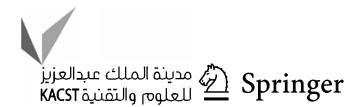


Table 1 Catalytic activities of 7a-7d for ethylene trimerization

\begin{tabular}{lllllll}
\hline Cat7 & $\mathrm{R}$ & MAO & $\begin{array}{l}\text { Productivity }(\mathrm{g} \\
\mathrm{C} / \mathrm{g} \mathrm{Cr} / \mathrm{h})\end{array}$ & $\mathrm{C}_{6}(\mathrm{wt} \%)$ & $1-\mathrm{C}_{6}(\mathrm{wt} \%)$ & $\mathrm{PE}(\mathrm{wt} \%)$ \\
\hline $7 \mathrm{a}$ & $\mathrm{Me}$ & 600 & 41,607 & 94.0 & 99.7 & 0.11 \\
$7 \mathrm{~b}$ & $\mathrm{Et}$ & 600 & 40,640 & 94.0 & 99.7 & 0.66 \\
$7 \mathrm{c}$ & ${ }^{\mathrm{n}} \mathrm{Bu}$ & 600 & 51,553 & 93.0 & 99.3 & 0.97 \\
$7 \mathrm{~d}$ & ${ }^{\mathrm{n}} \mathrm{Decyl}$ & 100 & 142,035 & 97.2 & 99.7 & 0.30 \\
\hline
\end{tabular}

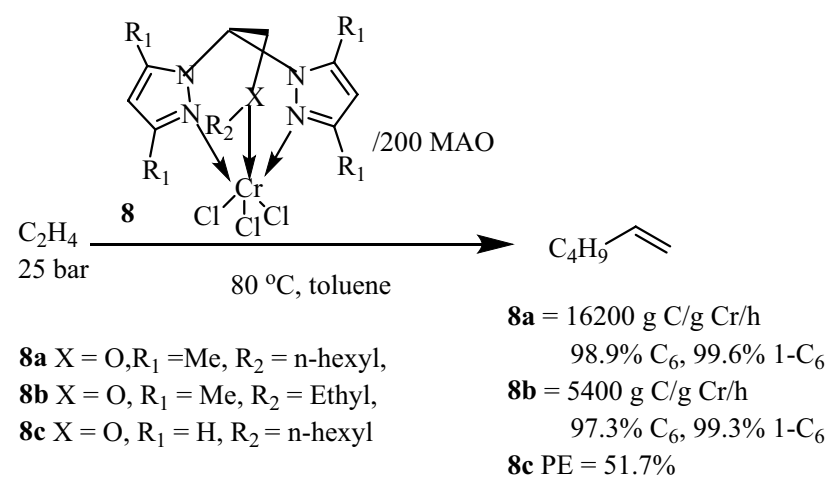

Scheme 10 [NON] and [NSN] Heteroscorpionate ligand-based catalyst system



Scheme 11 SABIC-Linde Cr-PNPN ligand-based catalyst system

Surprisingly the introduction of chloride additives such as $\left(\left[\mathrm{Ph}_{4} \mathrm{P}\right] \mathrm{Cl},\left[\mathrm{Et}_{4} \mathrm{~N}\right] \mathrm{Cl},\left[\mathrm{H}(\mathrm{Et})_{3} \mathrm{~N}\right] \mathrm{Cl},\left[\mathrm{H}(i \mathrm{Pr})_{3} \mathrm{~N}\right] \mathrm{Cl},\left[\mathrm{Pr}_{4} \mathrm{~N}\right] \mathrm{Cl}\right.$, etc. to the catalyst system $\left(\mathrm{Cr}(\mathrm{acac})_{3} / \mathbf{9} / \mathrm{Et}_{3} \mathrm{Al}\right.$ turned it into a high active system, better than the earlier one. As shown in Scheme 11, catalyst system exhibited productivity of $43.9 \mathrm{~kg}$ $\mathrm{C} / \mathrm{g} \mathrm{Cr} / \mathrm{h}$ with $\mathrm{C}_{6}$ selectivity of $93.4 \mathrm{wt} \%, 1-\mathrm{C}_{6}$ selectivity of $99.1 \mathrm{wt} \%$ (selectivity within $\mathrm{C}_{6}$ fraction) and $\geq \mathrm{C}_{12}$ oligomers of about $0.2 \mathrm{wt} \%$. The excellent characteristic of this new trimerization system, e.g. high selectivity to $\mathrm{C}_{6}$ with highest purity of the $1-\mathrm{C}_{6}$ fraction (99\% of 1-hexene) along with use of cheap activator $\mathrm{Et}_{3} \mathrm{Al}$ over expensive $\mathrm{MAO}$ and lower quantity of polymer by-product formation, make it a potential candidate for industrial applications[50].

\section{Chevron's Cr-phosphanylamidinate catalyst system}

Researchers from Chevron reported a new family of selective 1-hexene/1-octene catalysts based on N-phosphino amidine ligands [51, 52]. These ligands can be easily synthesized in



Scheme 12 Chevron's Phosphanylamidinate ligand-based catalyst system

high yields from simple, widely available precursors. The treatment of $\mathrm{N}$-phosphino amidine ligands with $\mathrm{CrCl}_{3}(\mathrm{THF})_{3}$ gives corresponding chromium complexes. These chromium complexes were tested for ethylene trimerization/tetramerization after activating with 400-800 equivalents of MMAO$3 \mathrm{~A}$ in cyclohexane at ethylene pressure of $60 \mathrm{bar}$ and hydrogen pressure of 2 bar.

Among these chromium complexes, catalyst 10 selectively oligomerized ethylene to 1-hexene, exhibiting excellent activity and gave the highly pure $\mathrm{C}_{6}$ fraction with trace amount of polymer (Scheme 12). But the catalysts with other substituents [52] afforded mixture of 1-hexene and 1-octene under similar conditions with selectivity for both products above $97 \%$. However, the 1-hexene selectivity (wt $\%$ of 1-hexene in the $\mathrm{C}_{6}$ fraction) decreased from 97.3 to $94.6 \mathrm{wt} \%$ upon reducing the reaction temperature from 70 to $50^{\circ} \mathrm{C}$ at ethylene pressure of $60 \mathrm{bar}$, while purity of 1-octene did not change significantly. The ratio of 1-hexene-to-1-octene can be tuned by changing the steric environment around chromium metal [53]. The extensive literature search showed that the catalyst 10 is the one most active catalyst $(54,670 \mathrm{~kg} \mathrm{C} /$ $\mathrm{mol} \mathrm{Cr} / \mathrm{h}, 70{ }^{\circ} \mathrm{C}, \mathrm{TOF}=560 \mathrm{~s}^{-1}$ ) for chromium catalysed ethylene trimerization reaction.

\section{Titanium-based catalyst systems}

A great deal of attention has been paid to non-chromiumbased catalytic systems for ethylene trimerization mainly due to toxic nature of chromium and to attain better catalyst activity. Among them, titanium-based catalyst systems are the most studied and are projected as the potential catalyst 
systems for ethylene trimerization. It should be noted that previously great success was achieved with alphabutol technology where titanium-based catalysts were used for ethylene dimerization reaction to give 1-butene. Till today, Axens has licensed its proprietary alphabutol technology to 30 units in all over the world with 1-butene production capacity of 708KTA. Out of many titanium catalyst systems for ethylene trimerization, the synthesis and catalytic activities of two important systems are discussed here.

\section{Ti-cyclopentadienyl catalyst system}

One of the real breakthroughs in the field of titanium catalyst-based selective ethylene trimerization is reported by Hessen and co-workers in 2001 [54]. They discovered that cyclopentadienyl ligand-based titanium complexes upon activation with 1,000 equivalent of MAO in toluene can produce predominantly 1-hexene. The catalyst precursor, i.e., cyclopentadienyl ligands were prepared by reaction of substituted fulvenes with the appropriate organolithium (RLi) salts. The resulting lithium cyclopentadienides, $\left[\mathrm{CpCMe}_{2} \mathrm{R}\right]$ $\mathrm{Li}$, quenched with trimethylsilyl chloride to afford the corresponding $\left(\mathrm{C}_{5} \mathrm{H}_{4} \mathrm{CMe}_{2} \mathrm{R}\right) \mathrm{SiMe}_{3}$ reagents which on reaction with $\mathrm{TiCl}_{4}$ afforded (cyclopentadienyl)titanium trichlorides. On the other hand, the $\left(\mathrm{CpCMe}_{2} \mathrm{R}\right) \mathrm{Li}$ on direct reaction with $\mathrm{TiCl}_{4}$ also gives (cyclopentadienyl)titanium trichlorides. (Cyclopentadienyl)titanium trichloride based catalyst 11, upon activation with 1000 equiv of MAO under 5 bar of ethylene pressure and ambient temperature in toluene could produce $\mathrm{C}_{6}$ products with productivity of $58.2 \mathrm{~kg} \mathrm{C}_{6} / \mathrm{g} \mathrm{Ti} / \mathrm{h}$ and selectivity of $83 \mathrm{wt} \%$ (Scheme 13). Additionally, 14 $\mathrm{wt} \%$ of $\mathrm{C}_{10}$ products and $1.8 \mathrm{wt} \%$ of the polymer formed in the above reaction.

The rate of production of $\mathrm{C}_{6}$ product and polymer increases with increasing ethylene pressure. At 10 bar of ethylene pressure, the $\mathrm{C}_{6}$ productivity goes up to $131.4 \mathrm{~kg}$ $\mathrm{C}_{6} / \mathrm{g} \mathrm{Ti} / \mathrm{h}$, with $2.6 \mathrm{wt} \%$ of polyethylene yield. However, the cyclopentadienyl ligand-based titanium catalysts suffer from poor thermal stability. With increasing reaction temperature, the overall catalyst productivity decreases along with increase in the formation of the polymer due to catalyst degradation.

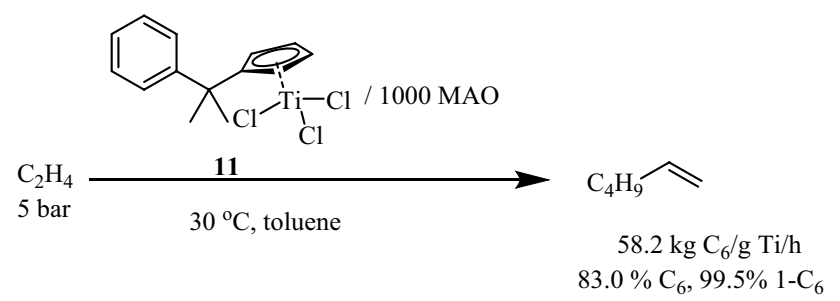

Scheme 13 Cyclopentadienyl ligand-based titanium catalyst system

\section{Mitsui chemicals Ti-phenoxy-imine catalyst system}

In 2010, another breakthrough in the field of titanium catalyst-based ethylene trimerization is reported by Fujita at Mitsui company [55]. During investigation of early transition metal-based bis(phenoxy-imine) complexes (also known as FI catalysts) for olefin polymerization [56], they discovered phenoxy-imine-ether ligated Ti complexes which are highly active after activation with MAO, to selectively trimerize ethylene to produce 1-hexene with exceptionally high productivity under mild conditions.

The catalyst precursor, the tridentate phenoxy-imine ligands were readily prepared by Schiff base condensations between the corresponding salicylaldehydes and primary amines. The corresponding titanium complexes were prepared by treating the Schiff base imines with $\mathrm{TiCl}_{4}$. As depicted in Scheme 14, complexes 12a, 12b and 12c were tested for ethylene trimerization with 1000 equivalents of MAO under 8 bar of ethylene pressure. Complex 12a, bearing a pendant aryl-OPh donor, exhibited 1-hexene productivity of $4 \mathrm{~kg} 1-\mathrm{C}_{6} / \mathrm{g}$ Ti/h with a considerable amount of polymer (23.4 wt\%). The higher selectivity for 1-hexene (86.2 wt $\%$ ) with extremely high productivity $\left(119 \mathrm{~kg} 1-\mathrm{C}_{6} / \mathrm{g} \mathrm{Ti} / \mathrm{h}\right)$ was obtained on using the complex $\mathbf{1 2 b}$, where a pendant $\mathrm{OPh}$ donor is replaced with OMe. This result shows that the introduction of the OMe group in place of the OPh group converted a poorly active ethylene trimerization catalyst into a highly active and selective ethylene trimerization catalyst, illustrating the effect of aryl-OR groups on catalyst performance. The complex 12c having an adamantyl group ortho to the phenoxy exhibited higher 1-hexene selectivity (91.4 $\mathrm{wt} \%)$ and activity (155 kg 1- $\left.\mathrm{C}_{6} / \mathrm{g} \mathrm{Ti} / \mathrm{h}\right)$ under optimized process conditions. At higher ethylene pressure, i.e. at 50 bar, 12c showed a significant enhancement of 1-hexene productivity of $6,590 \mathrm{~kg} 1-\mathrm{C}_{6} / \mathrm{g} \mathrm{Ti} / \mathrm{h}$ and TOF of $3.7 \times 10^{6} / \mathrm{h}$ with selectivity of $92.3 \mathrm{wt} \%$.

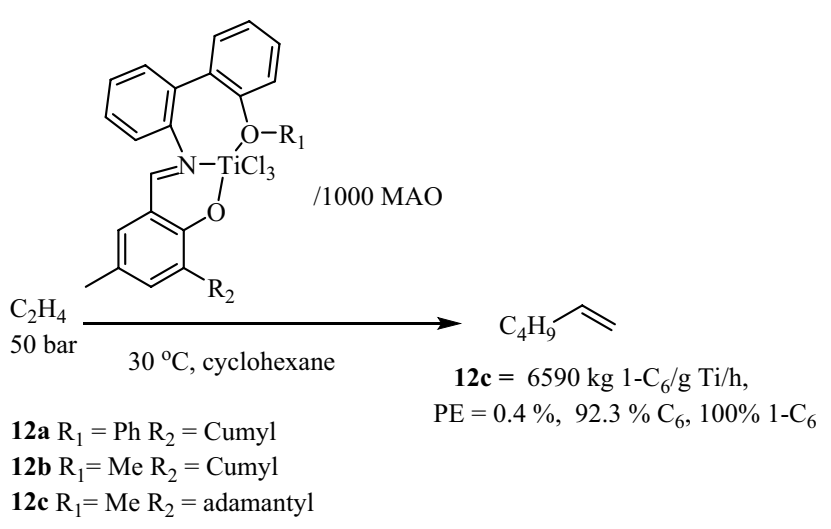

Scheme 14 Mitsui Chemical's phenoxy-imine ligand-based catalyst system

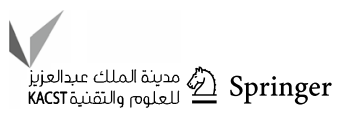


The activity observed in case of titanium-based catalysts are comparatively greater than that seen with the commercially employed Cr-based catalyst (Phillips catalyst) under same ethylene pressure. The main drawbacks of a titanium catalyst-based ethylene trimerization reaction are the requirement of 1,000 equivalents expensive cocatalyst, MAO to attain high catalytic activity. Additionally, ambient reaction temperature may pose a difficulty in handling the by-product polymer at heat exchanger in the manufacturing plant. Mitsui titanium catalysts known to deactivate at high temperature $\geq 45^{\circ} \mathrm{C}$ and produces polyethylene in major quantity [57]. However, in 2011, Mitsui Chemicals commercialized titanium-phenoxy-imine catalyst system-based ethylene trimerization technology with production capacity of 30kTA under a trade name of MET process [58].

\section{Outlook}

The field of selective olefin oligomerization has been developed tremendously since first report of selective ethylene trimerization by Phillips catalyst system. Progress has been made by finding more active and more selective catalysts and by developing nontoxic metal-based catalyst systems. Few of those catalysts can produce 1-hexene with high selectivity and productivity.

1-Hexene demand is growing due to increase in the rate of consumption of speciality polymers like LLDPE and HDPE in comparison to commodity polyethylene. Most of the recently developed catalysts require expensive activators. At the present scenario, catalysts that are activated by inexpensive activators or need only small amounts of expensive activator have the potential advantages for commercial applications. So, research should be focussed on developing self-activating type catalyst for high commercial viability [59]. In addition to that, from a environmental point of view, the generation of waste such as catalyst, activators residues, polymers and higher oligomers should be minimized, or it should be reused or blended with other products.

Some of nontoxic catalyst systems such as titanium catalyst system have been transformed into technology and commercialized on smaller scale capacity [58]. These catalysts need expensive ligands to be synthesized, and they degrade at higher temperatures. So, it is desirable to improve the catalytic system to scale-up the production capacity to larger scale. Additionally, it is very important to develop the catalyst preparation method which is easily scalable up to commercial scale. The focus on introduction of additives such as hydrogen, chlorides, diethylzinc, etc. to existing catalyst systems or during the ethylene trimerization may be worth to see in terms of the process optimization of ethylene trimerization reaction.

\section{Declarations}

Conflict of interest The authors declare no conflict of interest.

Open Access This article is licensed under a Creative Commons Attribution 4.0 International License, which permits use, sharing, adaptation, distribution and reproduction in any medium or format, as long as you give appropriate credit to the original author(s) and the source, provide a link to the Creative Commons licence, and indicate if changes were made. The images or other third party material in this article are included in the article's Creative Commons licence, unless indicated otherwise in a credit line to the material. If material is not included in the article's Creative Commons licence and your intended use is not permitted by statutory regulation or exceeds the permitted use, you will need to obtain permission directly from the copyright holder. To view a copy of this licence, visit http://creativecommons.org/licenses/by/4.0/.

\section{References}

1. Norbert P (1983) Branched polyethylene. LDPE and LLDPE. Ind Eng Chem Prod Res Dev 22:158-160

2. Jukka VS (1985) Copolymers of ethylene with butene-1 and long chain $\alpha$-olefins. I. Decene- 1 as long chain $\alpha$-olefin. J Appl Polym Sci 30:3545-3556

3. Liu P, Liu W, Wang WJ, Li BG, Zhu S (2016) A comprehensive review on controlled synthesis of long chain branched polyolefins: part 1, single catalyst systems. Macromol React Eng 10:156-179

4. Liu TM, Baker WE (1992) The effect of the length of the short chain branch on the impact properties of linear low-density polyethylene. Polym Eng Sci 32:944-955

5. https://pffc-online.com/magazine/1499-paper-effects-comon omer-type

6. Kaminsky W, Funck A, Hahnsen H (2009) New application for metallocenecatalysts in olefin polymerization. Dalton Trans 41:8803-8810

7. Yang Y, Kim H, Lee J, Paik H, Jang HG (2000) Roles of chloro compound in homogeneous $\left[\mathrm{Cr}(2 \text {-ethylhexanoate) })_{3} / 2,5\right.$ dimethyl pyrrole/triethylaluminum/chloro compound] catalyst system for ethylene trimerization. Appl Catal A: Gen 193:29-38

8. Dixon JT, Green MJ, Hess FM, Morgan DH (2004) Advances in selective ethylene trimerisation - a critical overview. J Organomet Chem 689:3641-3668

9. Agapie T (2011) Selective ethylene oligomerization: recent advances in chromium catalysis and mechanistic investigations. Coordin Chem Rev 255:861-880

10. Manyik RM, Walker WE, Wilson TP (1977) A soluble chromiumbased catalyst for ethylene trimerization and polymerization. $\mathrm{J}$ Catal 47:197-209

11. Briggs JR (1989) The selective trimerization of ethylene to hex1-ene. J. Chem. Soc. Chem Commun 11:674-675

12. Freeman JW, Buster JL, Knudsen RD (1999) Olefin production. US patent 5856257

13. IHS chemical special report - January 27 (2017) Light linear alpha olefins market study

14. https://www.cpchem.com/mediaevents/news/news-release/chevr on-phillips-chemical-announces-mechanical-completion-and-start

15. Freeman JW, Ewert WM, Kreischer BE, Knudsen RD, Cowan GD (2002) Olefin production. US Patent 6455648B1

16. Jabri A, Mason CB, Sim Y, Gambarotta S, Burchell TJ, Duchateau $\mathrm{R}$ (2008) Isolation of single-component trimerization and polymerization chromium catalysts: the role of the metal oxidation state. Angew Chem Int Ed 47:9717-9721 
17. Kulangara SV et al (2015) Effect of cocatalysts and solvent on selective ethylene oligomerization. Organometallics 34:1203-1210

18. Sydora OL (2013) Oligomerization catalyst system and process for oligomerizing olefins. US patent 8471085B2

19. Sydora O, Knudsen R, Baralt E (2013) Preparation of an olefin oligomerization catalyst. WO 2013089962 A1

20. Strem Chemicals Product No. 93-2426

21. Jeon JY et al (2015) Chromium precursor for Phillips ethylene trimerization catalyst: (2-ethylhexanoate) ${ }_{2} \mathrm{CrOH}$. Dalton Trans 44:11004-11012

22. Venderbosch B et al (2019) Spectroscopic investigation of the activation of a chromium-pyrrolyl ethene trimerization catalyst. ACS Catal 9:1197-1210

23. Steele RB, Katzakian AJ, Scigliano JJ, Hamel EE (1976) Imide oxirane reactions US patent 3962182A

24. Sydora OL et al (2018) A homoleptic chromium(iii) carboxylate. Dalton Trans 47:4790-4793

25. Tang S, Liu Z, Yan X, Li N, Cheng R, He X, Liu B (2014) Kinetic studies on the pyrrole-Cr-based Chevron-Phillips ethylene trimerization catalyst system. Appl Catal A: Gen 481:39-48

26. Zilbershtein TM, Kardash VA, Lipskikh MV, Suvorova VV, Golovko AK (2012) Kinetics of the ethylene trimerization reaction on a homogeneous chromium-pyrrole catalyst. Pet Chem 52:335-340

27. Zilbershtein TM, Kardash VA, Suvorova VV, Golovko AK (2014) Decene formation in ethylene trimerization reaction catalyzed by Cr-pyrrole system. Appl Catal A: Gen 475:371-378

28. Czaja K (2011) Białek M (2001) Effect of hydrogen on the ethylene polymerization process over Ziegler-Natta catalysts supported on $\mathrm{MgCl}_{2}(\mathrm{THF})_{2}$. I. Studies of the chain-transfer reaction. J Appl Polym Sci 79:356-360

29. Bahri-Laleh $\mathrm{N}$ et al (2018) $\mathrm{H} 2$ effect in Chevron-Phillips ethylene trimerization catalytic system: an experimental and theoretical investigation. Polym Bull 75:3555-3565

30. Jiang T, Zhang L, Gao J, Cao C (2016) Hydrogen: efficient promoter for PNP/Cr (III)/MAO catalyzed ethylene tetramerization toward 1-octene. Appl Petrochem Res 6:413-417

31. Miller WW et al (1999) Process for the trimerization of olefins. WO1999019280A1

32. Rensburg WJ et al (2004) A DFT study toward the mechanism of chromium - catalyzed ethylene trimerization. Organometallics 23:1207-1222

33. Yang Y et al (2014) Mechanistic DFT study on ethylene trimerization of chromium catalysts supported by a versatile pyrrole ligand system. Organometallics 33:2599-2607

34. Naji-Rad E, Gimferrer M, Bahri-Laleh N, Nekoomanesh-Haghighi M, Jamjah R, Poater A (2018) Exploring basic components effect on the catalytic efficiency of Chevron-Phillips catalyst in ethylene trimerization. Catalysts 8:224-234

35. Lattner JR et al (2011) System and method for selective trimerization, WO $2011112184 \mathrm{~A} 1$

36. Araki Y, Nakamura H, Nanba Y, Okanu T (1999) Process for producing $\alpha$-olefin oligomer. US patent $5856612 \mathrm{~A}$

37. Luo HK, Li DG, Li S (2004) The effect of halide and the coordination geometry of chromium center in homogeneous catalyst system for ethylene trimerization. J Mol Catal A: Chem 221:9-17

38. Meudon DC, Rueil Malmaison SD, Croissysur Seine LS (2000) Catalytic composition and process for oligomerising ethylene in particular to 1-butene and/or 1-hexene. US patent 6031145A

39. Commereuc D, Drochon S, Saussine L (2001) Catalytic composition and a process for oligomerizing ethylene, in particular to 1-hexene, US patent 20010023281A1

40. Morgan DH, Schwikkard SL, Dixon JT, Nair JJ, Hunterc R (2003) The effect of aromatic ethers on the trimerisation of ethylene using a chromium catalyst and aryloxy ligands. Adv Synth Catal 345:939-942

41. Carter A et al (2002) High activity ethylene trimerisation catalysts based on diphosphine ligands. Chem Commun (8):858-859

42. Wass DF (2002) Olefin trimerisation using a catalyst comprising a source of chromium, molybdenum or tungsten and a ligand containing at least one phosphorous, arsenic or antimony atom bound to at least one (hetero)hydrocarbyl group. WO 0204119 A1

43. Dossett SJ et al (2001) Steric activation of chelate catalysts: efficient polyketone catalysts based on four-membered palladium(II) diphosphine chelates. Chem Commun 8:699-700

44. Cooley NA et al (2001) Nickel ethylene polymerization catalysts based on phosphorus ligands. Organometallics 20:4769-4771

45. McGuinness DS et al (2003) Novel Cr-PNP complexes as catalysts for the trimerisation of ethylene. Chem Commun (3):334-335

46. McGuinness DS et al (2003) First Cr (III)-SNS complexes and their use as highly efficient catalysts for the trimerization of ethylene to 1-hexene. J Am Chem Soc 125:5272-5273

47. Zhang J, Braunstein P, Andy Hor TS (2008) Highly selective chromium (III) ethylene trimerization catalysts with [NON] and [NSN] heteroscorpionate ligands. Organometallics 27:4277-4279

48. Peitz S et al (2010) A selective chromium catalyst system for the trimerization of ethene and its coordination chemistry. Eur J Inorg Chem. https://doi.org/10.1002/ejic.201000044

49. Muller BH et al (2011) Activity enhancement of a catalyst system for the selective trimerization of ethene to 1-hexene by modification of the chromium to chloride to aluminium ratio. Chem Eur J 17:6935-6938

50. Suttil JA et al (2014) A survey of pendant donor-functionalised (N, O) phosphine ligands for Cr-catalysed ethylene tri- and tetramerisation. Catal Sci Technol 4:2574-2588

51. Sydora OL, Carney M, Small BL, Hutshison S, Gee JC (2011) Phosphinyl amidine compounds, metal complexes, catalyst systems, and their use to oligomerize or polymerize olefins. WO 2011082192A1

52. Sydora OL et al (2012) Selective ethylene Tri-/tetramerization catalysts. ACS Catal 2:2452-2455

53. Ogawa $\mathrm{T}$ et al (2021) Chromium N-phosphinoamidine ethylene tri-/tetramerization catalysts: designing a step change in 1-octene selectivity. J Catal 394:444-450

54. Deckers PJW, Hessen B, Teuben JH (2001) Switching a catalyst system from ethene polymerization to ethene trimerization with a hemilabile ancillary ligand. Angew Chem Int Ed 40:2516-2519

55. Fujita $\mathrm{T}$ et al (2010) Trimerization of ethylene to 1-hexene with titanium complexes bearing phenoxy-imine ligands with pendant donors combined with MAO. Organometallics 29:2394-2396

56. Makio H, Terao H, Iwashita A, Fujita T (2011) FI catalysts for olefin polymerization-a comprehensive treatment. Chem Rev 111:2363-2449

57. Cordier A et al (2020) Titanium-based phenoxy-imine catalyst for selective ethylene trimerization: effect of temperature on the activity, selectivity and properties of polymeric side products. Catal Sci Technol 10:1602-1608

58. https://jp.mitsuichemicals.com/en/release/2008/080623e.htm

59. Albahily K, Shaikh Y, Ahmed Z, Korobkov I, Gambarotta S, Duchateau R (2011) Isolation of a self-activating ethylene trimerization catalyst of a Cr-SNS system. Organometallics 30:4159-4164

Publisher's Note Springer Nature remains neutral with regard to jurisdictional claims in published maps and institutional affiliations. 